Disclosure of Interests: lain Mclnnes Grant/research support from: Bristol-Myers Squibb, Celgene, Eli Lilly and Company, Janssen, and UCB, Consultant of: AbbVie, Bristol-Myers Squibb, Celgene, Eli Lilly and Company, Gilead, Janssen, Novartis, Pfizer, and UCB, Frank Behrens Grant/research support from: Pfizer, Janssen, Chugai, Celgene, Lilly and Roche, Consultant of: Pfizer, AbbVie, Sanofi, Lilly, Novartis, Genzyme, Boehringer, Janssen, MSD, Celgene, Roche and Chugai, Philip J Mease Grant/research support from: Abbott, Amgen, Biogen Idec, BMS, Celgene Corporation, Eli Lilly, Novartis, Pfizer, Sun Pharmaceutical, UCB - grant/research support, Consultant of: Abbott, Amgen, Biogen Idec, BMS, Celgene Corporation, Eli Lilly, Novartis, Pfizer, Sun Pharmaceutical, UCB - consultant, Speakers bureau: Abbott, Amgen, Biogen Idec, BMS, Eli Lilly, Genentech, Janssen, Pfizer, UCB - speakers bureau, Arthur Kavanaugh Grant/research support from: Abbott, Amgen, AstraZeneca, BMS, Celgene Corporation, Centocor-Janssen, Pfizer, Roche, UCB - grant/research support, Christopher T. Ritchlin Grant/research support from: UCB Pharma, AbbVie, Amgen, Consultant of: UCB Pharma, Amgen, AbbVie, Lilly, Pfizer, Novartis, Gilead, Janssen, Peter Nash Grant/research support from: AbbVie, Bristol-Myers Squibb, Celgene, Eli Lilly and Company, Gilead, Janssen, MSD, Novartis, Pfizer Inc, Roche, Sanofi, UCB, Consultant of: AbbVie, Bristol-Myers Squibb, Celgene, Eli Lilly, Gilead, Janssen, MSD, Novartis, Pfizer Inc, Roche, Sanofi, UCB, Speakers bureau: AbbVie, Bristol-Myers Squibb, Celgene, Eli Lilly, Gilead, Janssen, MSD, Novartis, Pfizer Inc, Roche, Sanofi, UCB, Jordi Gratacos-Masmitja Grant/research support from: a grant from Pfizzer to study implementation of multidisciplinary units to manage PSA in SPAIN, Consultant of: Pfizzer, MSD, ABBVIE, Janssen, Amgen, BMS, Novartis, Lilly, Speakers bureau: Pfizzer, MSD, ABBVIE, Janssen, Amgen, BMS, Novartis, Lilly, Philippe Goupille Grant/research support from: AbbVie, Amgen, Biogen, BMS, Celgene, Chugai, Lilly, Janssen, Medac, MSD France, Nordic Pharma, Novartis, Pfizer, Sanofi and UCB, Consultant of: AbbVie, Amgen, Biogen, BMS, Celgene, Chugai, Lilly, Janssen, Medac, MSD France, Nordic Pharma, Novartis, Pfizer, Sanofi and UCB, Speakers bureau: AbbVie, Amgen, Biogen, BMS, Celgene, Chugai, Lilly, Janssen, Medac, MSD France, Nordic Pharma, Novartis, Pfizer, Sanofi and UCB, Tatiana Korotaeva Grant/research support from: Pfizer, Consultant of: Abbvie, BIOCAD, Bristol-Myers Squibb, Celgene, Eli Lilly, Janssen, Merck Sharp \& Dohme, Novartis, Novartis-Sandoz, Pfizer, UCB, Speakers bureau: Abbvie, BIOCAD, Bristol-Myers Squibb, Celgene, Eli Lilly, Janssen, Merck Sharp \& Dohme, Novartis, Novartis-Sandoz, Pfizer, UCB, Alice B Gottlieb Grant/research support from:: Research grants, consultation fees, or speaker honoraria for lectures from: Pfizer, AbbVie, BMS, Lilly, MSD, Novartis, Roche, Sanofi, Sandoz, Nordic, Celltrion and UCB., Consultant of:: Research grants, consultation fees, or speaker honoraria for lectures from: Pfizer, AbbVie, BMS, Lilly, MSD, Novartis, Roche, Sanofi, Sandoz, Nordic, Celltrion and UCB., Speakers bureau:: Research grants, consultation fees, or speaker honoraria for lectures from: Pfizer, AbbVie, BMS, Lilly, MSD, Novartis, Roche, Sanofi, Sandoz, Nordic, Celltrion and UCB., Ruvie Martin Shareholder of: Novartis, Employee of: Novartis, Kevin Ding Employee of: Novartis, Pascale Pellet Shareholder of: Novartis, Employee of: Novartis, Shephard Mpofu Shareholder of: Novartis, Employee of: Novartis, Luminita Pricop Shareholder of: Novartis, Employee of: Novartis

DOI: 10.1136/annrheumdis-2020-eular.4129

\begin{tabular}{|l|l}
\hline OP0228 & EFFICACY AND SAFETY OF IXEKIZUMAB VERSUS \\
& ADALIMUMAB (SPIRIT-H2H) WITH AND WITHOUT \\
& CONCOMITANT CONVENTIONAL SYNTHETIC \\
& DISEASE-MODIFYING ANTIRHEUMATIC DRUGS \\
& (DMARD) IN BIOLOGIC DMARD-NAÏVE PATIENTS WITH \\
& PSORIATIC ARTHRITIS: 52-WEEK RESULTS
\end{tabular}

J. S. Smolen ${ }^{1}$, A. Sebba ${ }^{2}$, E. Ruderman ${ }^{3}$, A. Gellett ${ }^{4}$, C. Sapin ${ }^{4}$, A. T. Sprabery ${ }^{4}$, S. Liu Leage ${ }^{4}$, S. Pillai ${ }^{4}$, P. Reis ${ }^{4}$, P. Nash ${ }^{5} .{ }^{1}$ Medical University of Vienna, Vienna, Austria; ' ${ }^{2}$ University of South Florida, Tampa, United States of America; ${ }^{3}$ Northwestern Medical Group, Chicago, United States of America; ${ }^{4}$ Eli Lilly and Company, Indianapolis, United States of America; ${ }^{5}$ School of Medicine, Griffiths University, Brisbane, Australia

Background: Ixekizumab (IXE), a high-affinity monoclonal antibody selectively targeting IL-17A, was superior to adalimumab (ADA) at Week (Wk) 24 for simultaneous achievement of ACR50 and 100\% improvement from baseline in the Psoriasis Area and Severity Index (PASI 100) (primary endpoint) in patients (pts) with active PsA from SPIRIT-H2H ${ }^{1}$. SPIRIT-H2H had two major secondary endpoints and achieved both: noninferiority of IXE to ADA for ACR50 at Wk 24, and superiority of IXE to ADA for PASI 100 at Wk 24.

Objectives: To determine how concomitant conventional synthetic DMARD (csDMARD) use affects safety and efficacy of IXE and ADA in prespecified subgroups defined by biologic monotherapy, concomitant MTX use, and concomitant csDMARD use through Wk 52 in SPIRIT-H2H.

Methods: SPIRIT-H2H (NCT03151551) was a 52-week, multicentre, randomised, open-label, assessor-blinded, parallel-group study evaluating the efficacy and safety of IXE versus ADA in adults with PsA and naïve to biologic DMARDs. Patients were required to have active PsA fulfilling Classification for Psoriatic Arthritis (CASPAR) criteria and $\geq 3 / 68$ tender and $\geq 3 / 66$ swollen joints, $\geq 3 \%$ plaque psoriasis BSA involvement, no prior treatment with bDMARDs, and with prior inadequate response to $\geq 1$ csDMARD (but not necessarily current treatment with cSDMARDs). Randomization (1:1) was stratified by concomitant use of csDMARD and the presence/absence of moderate to severe PsO (baseline: $B S A \geq 10 \%+P A S I \geq 12$, + static Physician's Global Assessment $\geq 3$ ). Patients $(\mathrm{N}=566)$ received IXE/ADA through 52 wks according to the labelled dose dependent on presence/absence of moderate-to-severe $\mathrm{PsO}$. In this prespecified subgroup analysis by presence or absence of csDMARDs, efficacy outcomes through wk 52 were compared between IXE and ADA using logistic regression models and Fisher's exact tests. Missing data were imputed using non-responder imputation.

Results: At baseline, 167 of 283 IXE-treated patients and 169 of 283 ADAtreated patients had concomitant MTX use. Of these, 9.0\% (15/167) and $7.1 \%$ (12/169) treated with IXE and ADA, respectively, were taking an additional csDMARD (sulfasalazine, cyclosporine, or leflunomide). A significantly greater proportion of patients on IXE versus ADA achieved the primary endpoint or PASI 100 when used as monotherapy or in combination with csDMARD (Figure $1 \mathrm{~A}$ and $1 \mathrm{C}$ ). At Wk 52, the proportion of patients achieving ACR50 was not statistically different between IXE and ADA, regardless of monotherapy or concomitant csDMARD use (Figure 1B). A significantly higher proportion of patients achieved MDA on IXE compared to ADA in the monotherapy subgroup ( $49 \%$ vs $33 \%)$, while the response rates were similar in both combination subgroups (Figure 1D). These data support consistent ACR50, PASI 100, and MDA response for IXE across all three subgroups. Frequencies of adverse events were similar across the three subgroups for IXE and ADA (Figure 2)

Conclusion: As with prior studies, ${ }^{2,3}$ consistent efficacy across multiple PsA disease-specific endpoints was observed with IXE in SPIRIT-H2H, regardless of whether IXE was taken as monotherapy or in combination with MTX or another csDMARD. No unexpected safety signals were found for either agent. References:

[1] Mease et al, Ann Rheum Dis 2020;79:123-31.

[2] Coates et al, RMD Open 2017;3:e000567.

[3] Nash et al, RMD Open 2018;4:e000692.

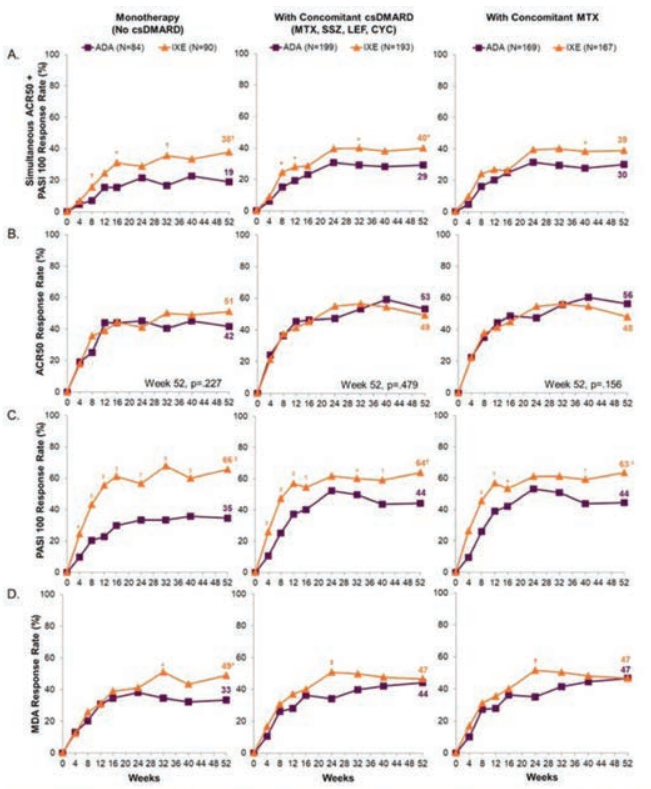

Figure 1. Proportion patients through 52 weeks with simultaneous achievement of ACR50 + PASI 100, ACR50, PASI 100. and MDA-18 Entheseal Points. Nine patients with active $P S O$ and $B S A \geq 3 \%$ were assessed as $P A S I=0$ at baseline, a medica inconsistency that was resolved using medical judgement. These patients were cons
and $B S A=0$ at $p o s t$ baseline visit. " $p \leq .05$ vs. ADA; $p<.01$ vs. ADA; $p \leq .001$ vs. ADA.

Abbreviations: $A C R$, American College of Rheumatology criteria; $A D A$, adalimumab; CSDMARD, conventional synthetic DMARD; IXE, ixekizumab; MTX, methotrexate; MDA, minimal disease activity - PSA; PASI, Psoriasis Area Severity Index score. 

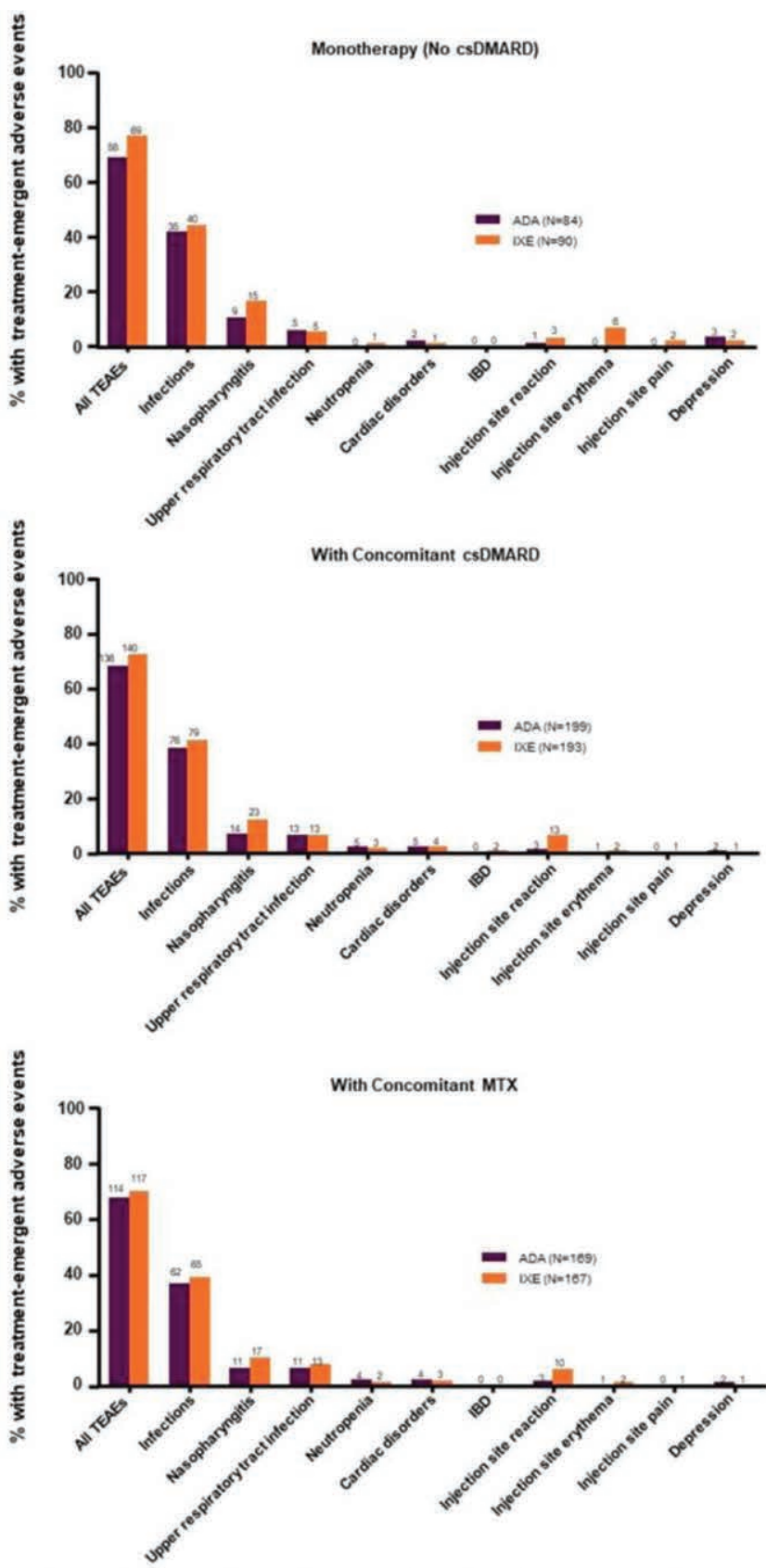

Safety data for patients through 52 weeks. 2 events of IBD were reported in the ixekizumab treatment arm but only 1 case met the adjudication criteriaof confirmed inflammatory bowel disease. Abbreviations: ADA, adalimumab; csDMARD, conventional synthetic DMARD; IBD, inflammatory bowel disease; IXE, ixekizumab; MTX, methotrexate; TEAE, treatment emergent adverse event.

Disclosure of Interests: Josef S. Smolen Grant/research support from: AbbVie, AstraZeneca, Celgene, Celltrion, Chugai, Eli Lilly, Gilead, ILTOO, Janssen, Novartis-Sandoz, Pfizer Inc, Samsung, Sanofi, Consultant of: AbbVie, AstraZeneca, Celgene, Celltrion, Chugai, Eli Lilly, Gilead, ILTOO, Janssen, Novartis-Sandoz, Pfizer Inc, Samsung, Sanofi, Anthony Sebba Consultant of: Genentech, Gilead, Lilly, Regeneron Pharmaceuticals Inc., Sanofi, Speakers bureau: Lilly, Roche, Sanofi, Eric Ruderman Consultant of: Pfizer, Amanda Gellett Shareholder of: Eli Lilly and Company, Employee of: Eli Lilly and Company, Christophe Sapin Shareholder of: Eli Lilly and Company, Employee of: Eli Lilly and Company, Aubrey Trevelin Sprabery Shareholder of: Eli Lilly and Company, Employee of: Eli Lilly and Company, Soyi Liu Leage Shareholder of: Eli Lilly and Company, Employee of: Eli Lilly and Company, Sreekumar Pillai Shareholder of: Eli Lilly and Company, Employee of: Eli Lilly and Company, Paulo Reis Shareholder of: Eli Lilly and Company, Employee of: Eli Lilly and Company, Peter Nash
Grant/research support from: AbbVie, Bristol-Myers Squibb, Celgene, Eli Lilly and Company, Gilead, Janssen, MSD, Novartis, Pfizer Inc, Roche, Sanofi, UCB, Consultant of: AbbVie, Bristol-Myers Squibb, Celgene, Eli Lilly, Gilead, Janssen, MSD, Novartis, Pfizer Inc, Roche, Sanofi, UCB, Speakers bureau: AbbVie, Bristol-Myers Squibb, Celgene, Eli Lilly, Gilead, Janssen, MSD, Novartis, Pfizer Inc Roche, Sanofi, UCB DOI: 10.1136/annrheumdis-2020-eular.4615

\section{OP0229 GUSELKUMAB INDUCES SUSTAINED REDUCTION IN ACUTE PHASE PROTEINS AND TH17 EFFECTOR CYTOKINES IN ACTIVE PSORIATIC ARTHRITIS IN TWO PHASE-3 CLINICAL TRIALS (DISCOVER-1 AND DISCOVER-2)}

S. Siebert ${ }^{1}$, I. Mcinnes ${ }^{1}$, M. J. Loza ${ }^{2}$, K. MA ${ }^{2}$, K. Leander, ${ }^{2}$,

V. Lakshminarayanan ${ }^{2}$, C. Franks ${ }^{2}$, P. Cooper ${ }^{2}$, K. Sweet ${ }^{2}{ }^{1}$ Univ Glasgow, Glasgow, United Kingdom; '2Janssen Research \& Development, LLC, Spring House, United States of America

Background: Guselkumab (GUS), an IL-23 inhibitor monoclonal antibody (Mab) that specifically binds to the IL-23p19 subunit, demonstrated efficacy compared to placebo (PBO) in reducing skin and musculoskeletal signs and symptoms in patients (pts) with active psoriatic arthritis (PsA) in two phase-3 studies, DISCOVER $1 \& 22^{1,2}$ Previous results from a GUS PsA Phase-2 trial ${ }^{3}$ and Ustekinumab (UST, anti-IL12/23p40 MAb) PsA Phase-3 trials (PSUMMIT 1 \& 2) showed associations of baseline IL-17A, IL-17F, and CRP with baseline disease characteristics, and associations of GUS-induced cytokine reductions with clinical responses.

Objectives: To investigate plausible cytokine expression in PsA and alterations after exposure to GUS therapy.

Methods: In DISCOVER 1 \& 2, pts were treated with GUS $100 \mathrm{mg}$ at Wk 0, 4, then every 8 Wks (q8w); GUS $100 \mathrm{mg}$ q $4 \mathrm{w}$; or matching PBO. 21 serum biomarkers were measured in a random subset of 300 PsA pts from the DISCOVER program at Weeks (Wks) 0, 4, \& 24 and in 34 healthy controls matched for age, sex, and ethnicity. Serum proteins measured were acute phase reactants CRP \& SAA (Meso Scale Discovery (MSD) Platform) and inflammatory cytokines/ chemokines: Th17 effector cytokines IL-17A, IL-17F, \& IL-22 (Single Molecule Counting Erenna ${ }^{\circledR}$ Immunoassay Platform) and soluble ICAM-1, soluble VCAM1, IL-6, CXCL-8, IL-10, IL-13, IL-12p70, CCL22, IFN- $\gamma$, CCL2, CCL4, TNFa, IL-1ß, IL-2, IL-4 (MSD), \& YKL-40 (Quantikine Immunoassay). Serum IL-17A, IL-17B, \& CRP measured in the Phase-3 PSUMMIT trials of UST for PsA $\mathrm{P}^{4}$ were included for comparison with GUS.

Results: At baseline, serum levels of acute phase proteins CRP, SAA, \& IL-6, and Th17-effector cytokines IL-17A \& IL-17F were elevated in pts with PsA compared with healthy controls ( $<<0.05$, geometric mean $\geq 40 \%$ higher, FIG 1). There was no significant dysregulation in the other cytokines measured in PsA pts compared to healthy controls. Baseline IL-17A, IL-17F, IL-22, \& CCL22 were significantly associated with baseline psoriasis disease activity (Body Surface Area \& Psoriatic Area and Severity Index, Spearman Signed Rank $p<0.05, r>0.25$ ). Baseline CRP, SAA, IL-6, \& YKL40 were significantly associated with baseline joint disease (Disease Activity Score 28-CRP, Spearman $p<0.05, r>0.25$ ). Baseline SAA, IL-6, IL-17A, \& IL-17F were higher in pts with prior TNF inhibitor exposure than without $(p<0.05$, geometric mean $\geq 40 \%$ higher), although pts with PsA both with and without prior TNF inhibitor had higher levels than the healthy control set.

GUS treatment resulted in decreases in serum CRP, SAA, IL-6, IL-17A, IL-17F, \& IL-22 that were significantly greater than PBO as early as Week 4 (FIG 1). These protein levels continued to decrease through Wk 24 in GUS-treated pts with both dosing regimens $(p<0.05$, geometric mean decrease from baseline $\geq 33 \%$ ). Further, Wk 24 IL-17A \& IL-17F levels for pts treated with either dose of GUS were not significantly different from healthy controls, suggesting a normalization of peripheral effector cytokines associated with the IL-23/Th17 axis following treatment with GUS. Effects on IL-17A/IL-17F were greater in GUS treated pts than UST treated pts, while CRP levels were similar in both programs (FIG 2).

Conclusion: Comprising a strong pharmacodynamic effect, GUS treatment reduced serum protein levels of acute phase and Th17-effector cytokines (whose elevations at baseline were associated with PsA disease characteristics) and achieved comparable levels to those in healthy controls. In pts with PsA, reductions of IL-17A and IL-17F by GUS were of greater magnitude than those by UST. References:

[1] Deodhar et al. ACR 2019, abs \#807. Arth Rheumatol. 2019;71 S10: 1386

[2] Mease et al. ACR 2019, abs \#L13. Arth Rheumatol. 2019;71 S10:5247

[3] Siebert et al. EULAR 2019, abs \#479. Ann Rheum Dis. 2019;78 S2:293

[4] Siebert et al. Arth Rheumatol. 2019;71:1660 